\title{
Excellent uricosuric efficacy of benzbromarone in cyclosporin-A-treated renal transplant patients: a prospective study
}

\author{
R. M. Zürcher, H. A. Bock, G. Thiel \\ Division of Nephrology, Department of Medicine, University Hospital Basel, Switzerland
}

\begin{abstract}
Patients on cyclosporin A (CsA) often develop hyperuricaemia and gout. In transplant patients the use of uricosuric drugs for treating hyperuricaemia may be preferable to allopurinol because of the known interaction of the latter with azathioprine. We therefore prospectively studied the uricosuric efficacy of $100 \mathrm{mg}$ benzbromarone (Bbr;Desuric ${ }^{(B)}$ ) daily in $25 \mathrm{CsA}$-treated renal transplant patients with stable graft function and hyperuricaemia $(>359 \mu \mathrm{mol} / \mathrm{l}$ for females, $>491 \mu \mathrm{mol} / \mathrm{l}$ for males).

Benzbromarone decreased plasma uric acid from $579 \pm 18 \mu \mathrm{mol} / 1$ to $313 \pm 24 \mu \mathrm{mol} / 1$ (mean \pm SEM; $P<$ 0.001 ) and thereby normalized plasma uric acid in 21 of 25 patients. The remaining four patients had creatinine clearances between 21 and $25 \mathrm{ml} / \mathrm{min}$, the lowest of the entire study group. Mean fractional clearance of uric acid increased from $5.4 \pm 0.4 \%$ to $17.2 \pm 1.0 \%$ $(P<0.001)$. The relative decrease of plasma uric acid closely correlated with baseline creatinine clearance $(r=0.67 ; P<0.001)$. CsA trough values were not influenced. None of the patients experienced any significant side-effects. As an unexpected find-ing, urinary uric acid excretion increased from $2082 \pm 175 \mu \mathrm{mol} / 24 \mathrm{~h}$ to $3233 \pm 232 \mu \mathrm{mol} / 24 \mathrm{~h}$ after 4 weeks' treatment with benzbromarone.

In conclusion, benzbromarone normalized plasma uric acid in all CsA-treated renal transplant recipients with a creatinine clearance $>25 \mathrm{ml} / \mathrm{min}$. Due to its excellent efficacy and lack of significant side-effects, benzbromarone appears to be preferable to allopurinol in CsA-treated renal transplant recipients with a creatinine clearance over $25 \mathrm{ml} / \mathrm{min}$.
\end{abstract}

Key words: cyclosporin A; kidney transplant; hyperuricaemia; uric acid excretion; benzbromarone; uricosuric efficacy

\section{Introduction}

Transplant patients on cyclosporin A (CsA) have a greater prevalence of hyperuricaemia than patients on

Correspondence and offprint requests to: Regula Zurcher MD, Department of Internal Medicine, HCUG, CH-12U Genève 14, Switzerland conventional immunosuppression [1]. Asymptomatic hyperuricaemia occurs in up to $80 \%$ of patients, gout in $5-24 \%$ of patients $[2,3]$. A substantial number of patients therefore need treatment for hyperuricaemia. Since hyperuricaemia in these patients is mainly due to reduced renal uric acid clearance and not to increased uric acid production [3], increasing uric acid elimination via the kidney is a sensible approach. Moreover the interaction of allopurinol with azathioprine, which can lead to life-threatening leukopenia, militates against the use of allopurinol in patients on combined immunosuppression with CsA and azathioprine. Since the efficacy of uricosuric drugs has never been formally evaluated in CsA-treated renal transplant patients, we undertook a prospective study to answer the following questions: does the uricosuric drug benzbromarone effectively lower plasma uric acid in CsA-treated renal transplant patients? Is there a lower limit of graft function for the uricosuric effect? Does benzbromarone cause any significant drug interaction or side-effects in these patients?

\section{Subjects and methods}

Twenty-five consecutive CsA-treated renal transplant patients (10 females, 15 males) with stable graft function and hyperuricaemia were studied prospectively after giving written informed consent. Inclusion criteria were: (1) CsA therapy with $(n=14)$ or without $(n=11)$ azathioprine and/or prednisone, (2) hyperuricaemia (>359 $\mu \mathrm{mol} / 1$ for females, $>491 \mu \mathrm{mol} / \mathrm{l}$ for males), (3) stable graft function. Exclusion criteria were: (1) current treatment with any uricosuric drug or allopurinol, (2) unstable graft function, (3) known poor compliance. Two patients in the study group had a history of gout. After baseline measurements, the patients received $100 \mathrm{mg}$ of benzbromarone daily for 4 weeks in addition to their established medication. No specific prescriptions regarding minimal fluid intake or urine alkalinization were given. Patients were asked for side-effects at 1 and 4 weeks of treatment. The following laboratory tests were performed at the beginning and at the end of the study: whole blood chemistry profile; platelet, red and white blood cell count; CsA blood trough levels; 24-h urine excretion of creatinine, urea, uric acid, protein, and calcium; microscopic examination of urine sediment. In addition the same examinations 
except 24-h urine analysis were performed after 1 week of treatment to detect early signs of toxicity or drug interaction.

\section{Laboratory methods}

Uric acid concentrations in plasma and urine were measured using a uricase method (Hitachi 737, Boehringer Mannheim), plasma and urine creatinine concentrations by a creatininase assay (Wako Chemicals GmbH, Neuss; Hitachi 737, Boehringer Mannheim). CsA whole blood $12 \mathrm{~h}$ trough values were measured with a TDx-FPIA-method (Abbott TDx cyclosporin monoclonal).

\section{Statistical analysis}

Statistical evaluation was performed using Student's paired $t$ test. Correlations were evaluated using linear least squares regression; $P<0.05$ was considered significant and two-sided tests were used throughout. Data are given as mean \pm SEM.

\section{Results}

Plasma creatinine of the study patients ranged between $82 \mu \mathrm{mol} / 1$ and $276 \mu \mathrm{mol} / 1$, creatinine clearance between 21 and $78 \mathrm{ml} / \mathrm{min}$. Graft function remained stable throughout the study period (Table 1 ).

Benzbromarone significantly decreased mean plasma uric acid from $579 \pm 18 \mu \mathrm{mol} / \mathrm{l}$ to $313 \pm 24 \mu \mathrm{mol} / \mathrm{l}$ $(P<0.001$; Table 1$)$. Fall of plasma uric acid was rapid and sustained in all but two patients (Figure 1), and there was no significant change beyond the first week for the group as a whole. For 21 of 25 patients this decrease meant normalization of plasma uric acid. Fractional uric acid clearance increased from $5.4 \pm 0.4 \%$ to $17.2 \pm 1.0 \%(P<0.001$; Table 1$)$. There was a good correlation between the percent decrease of plasma uric acid and both plasma creatinine $(r=$ $-0.68 ; P<0.001$; Figure 2$)$ and creatinine clearance ( $r=0.67 ; P<0.001$; Figure 3 ). Similarly, the increase of fractional uric acid clearance correlated well with creatinine $(r=-0.54 ; P<0.005)$ and creatinine clearance $(r=0.58 ; P<0.005)$. The four patients in whom normalization of plasma uric acid was not achieved had creatinine clearances between 21 and $25 \mathrm{ml} / \mathrm{min}$, the lowest of the whole study group.

While 24-h urinary creatinine excretion remained unchanged $(9885 \pm 2540 \mu \mathrm{mol} / 24 \mathrm{~h}$ versus $9971 \pm 2377$

Table 1. Results

\begin{tabular}{lccc}
\hline & Before Bbr & 1 week Bbr & 4 weeks Bbr \\
\hline CCR $(\mathrm{ml} / \mathrm{min})$ & $49 \pm 4$ & & $47 \pm 4$ \\
P-UA $(\mu \mathrm{mol} / 1)$ & $579 \pm 18$ & $281 \pm 20^{* * *}$ & $313 \pm 24^{* * *}$ \\
fCUA $(\%)$ & $5.4 \pm 0.4$ & & $17.2 \pm 1.0^{* * *}$ \\
UVUA $(\mu \mathrm{mol} / 24 \mathrm{~h})$ & $2082 \pm 175$ & $3233 \pm 232^{* *}$ \\
UVCreat $(\mu \mathrm{mol} / 24 \mathrm{~h})$ & $9885 \pm 2541$ & $9971 \pm 2377$ \\
CsA trough level $(\mu \mathrm{g} / 1)$ & $162 \pm 80$ & $162 \pm 72$ \\
\hline
\end{tabular}

Data are given as mean $\pm \mathrm{SEM} ; * * P<0.01 ; * * * P<0.001$.

Creatinine clearance (CCR), plasma uric acid (P-UA), fractional clearance of uric acid (fCUA), urinary excretion of uric acid (UVUA), urinary excretion of creatinine (UVCreat).
Plasma uric acid

رmoln

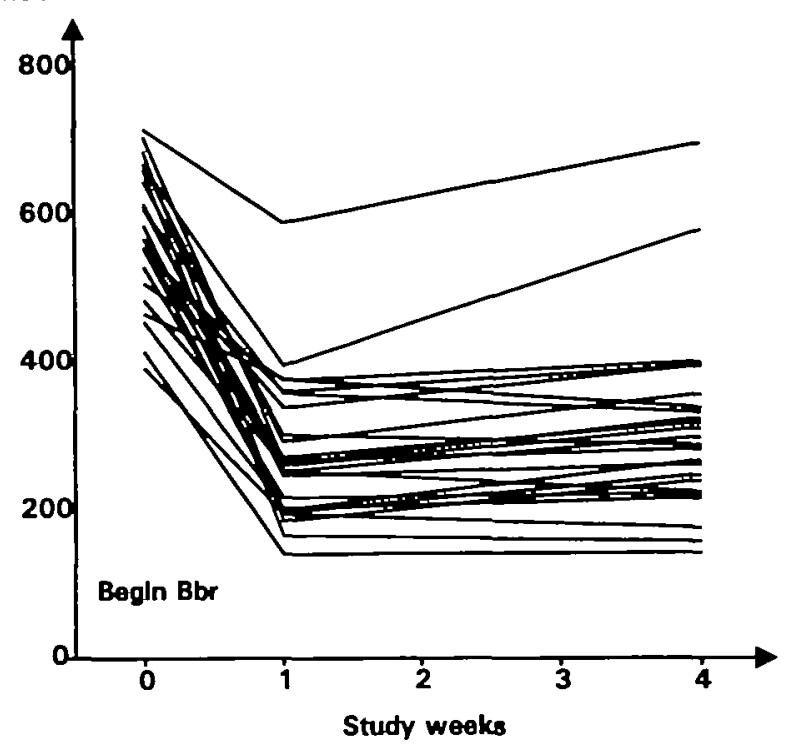

Fig. 1. Plasma uric ( $\mu \mathrm{mol} / 1)$ act before, during, and at the end of benzbromarone $(\mathrm{Bbr})$ treatment.

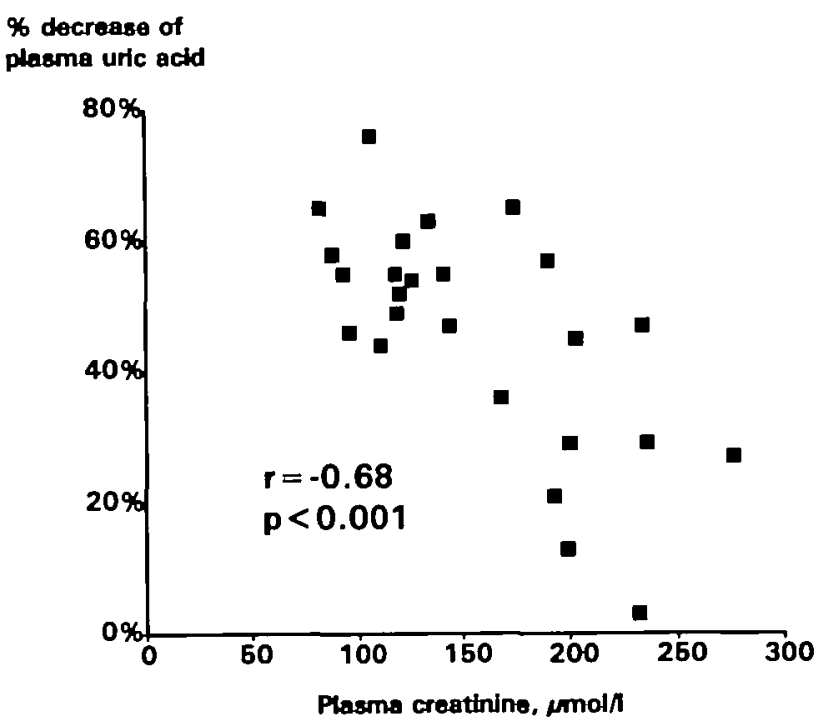

Fig. 2. Relative decrease (in percent of initial values) of plasma uric acid in function of plasma creatinine.

$\mu \mathrm{mol} / 24 \mathrm{~h}$ ), urinary uric acid excretion was significantly increased at the end of the 4 weeks treatment $(2082 \pm 175 \mu \mathrm{mol} / 24 \mathrm{~h}$ before $\mathrm{Bbr}, 3233 \pm 232$ $\mu \mathrm{mol} / 24 \mathrm{~h}$ after 4 weeks of Bbr, $P<0.001$ ). Only two patients' uric acid excretion, however, was in the hyperuricosuric $(>4800 \mu \mathrm{mol} / 24 \mathrm{~h})$ range, namely $4862 \mu \mathrm{mol} / 24 \mathrm{~h}$ and $7105 \mu \mathrm{mol} / 24 \mathrm{~h}$. Microscopic evaluation of urine sediment revealed no pathological microhaematuria nor crystalluria during treatment. There were no changes of CsA trough levels (162 \pm 80 before versus $162 \pm 72 \mu \mathrm{g} / \mathrm{l}$ after $\mathrm{Bbr}$ ) and no signs of toxicity in the haematological or in the blood chemistry profile. Except for one patient with known irritable colon who reported increased diarrhoea, no side-effects 


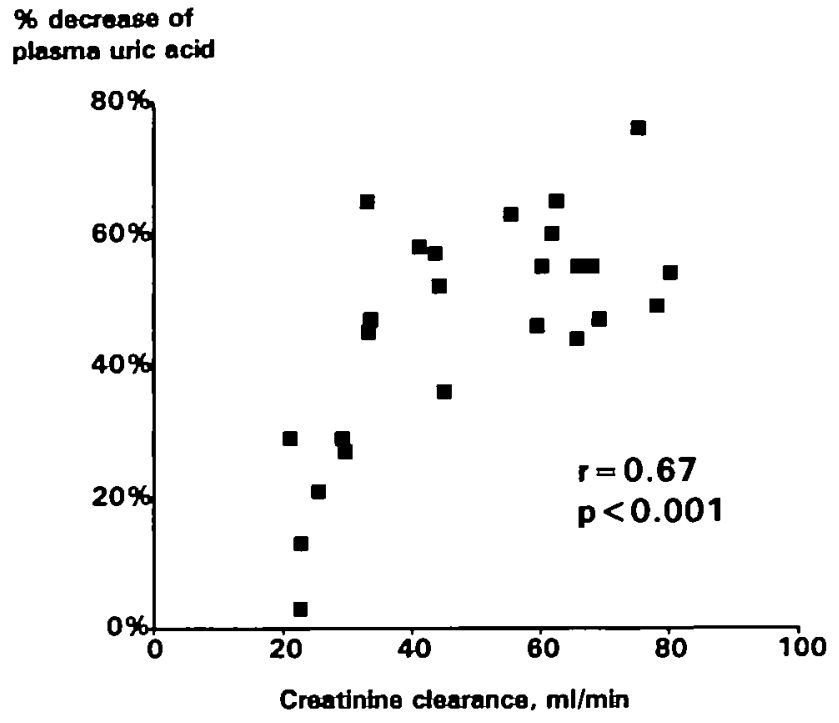

Fig. 3. Relative decrease (in percent of initial values) of plasma uric acid in function of creatinine clearance.

were noted. There were no episodes of gout or any evidence of urolithiasis.

\section{Discussion}

The efficacy of uricosuric drugs, well-documented in gouty, non-transplant patients [4], has not been formally evaluated in CsA-treated renal transplant patients so far. The use of uricosurics in these patients could be questioned because (a) reduced GFR $[5,6]$ and (b) impaired tubular handling of uric acid due to CsAinduced proximal tubular dysfunction [7-11] could potentially impair their effect. The present data, however, demonstrate an excellent efficacy of benzbromarone in lowering plasma uric acid within 1 week in all patients with a creatinine clearance $>25 \mathrm{ml} / \mathrm{min}$. Even in the four patients with a creatinine clearance $<25 \mathrm{ml} / \mathrm{min}$ there was still a moderate effect at 1 week (fall of plasma uric acid $17-41 \%$ ). The fact that this effect was not sustained in two of these patients, may be due to non-compliance. Similar results have been reported in non-transplant patients with comparable renal function $[6,12,13]$ as well as in a group of renal transplant patients on conventional immunosuppression [14]. There is therefore no evidence for impaired uricosuric efficacy of benzbromarone in CsA-treated renal transplant patients. That benzbromarone is less effective in patients with low creatinine clearances most probably reflects diminished postsecretory reabsorption in the renal tubule such as occurs with increasing renal failure $[15,16]$. Postsectretory reabsorption is the presumptive site of action of uricosuric drugs [17].

The $50 \%$ increase of urinary uric acid excretion (Table 1) after 4 weeks of benzbromarone represents an interesting, albeit unanticipated finding. Our expectation was that despite the increment in clearance, urinary excretion of uric acid would return to baseline by reaching a new steady state after 4 weeks' treatment with benzbromarone. Two possible mechanisms may be considered: either steady state conditions were not yet achieved because some of the patients were still mobilizing uric acid from soft tissue microdeposits, or extrarenal (mainly intestinal) uric acid excretion might have decreased with decreasing plasma uric acid $[18,19]$ and therefore a higher percentage of daily uric acid load was excreted via the kidney. Still, true hyperuricosuria $(>4500 \mu \mathrm{mol} / 24 \mathrm{~h}$ for females, $>4800 \mu \mathrm{mol} / 24 \mathrm{~h}$ for men) occurred in only two patients. Microscopic analysis of urine sediment never gave any evidence of increased crystalluria or haematuria. Since intratubular flow in the distal nephron of renal transplant patients (having only one functioning kidney) is greater than in normals, their risk of stone formation is probably lower at any degree of uric acid excretion. Of course, a larger and longer study would be required to ascertain that this risk is indeed not increased. In our personal experience, following 12 renal transplant patients for at least 1.5 years (median 4 years, range 1.5-6 years), we never observed any stone formation.

We conclude that benzbromarone is an efficacious and safe drug for treating hyperuricaemia in CsAtreated renal transplant patients with a creatinine clearance over $25 \mathrm{ml} / \mathrm{min}$. In patients with creatinine clearances below $25 \mathrm{ml} / \mathrm{min}$ or plasma creatinine over approximately $250 \mu \mathrm{mol} / 1$, allopurinol probably remains the preferred drug. Either treatment, however, should be given to symptomatic patients only.

\section{References}

1. European Multicenter Trial Group. Cyclosporin in cadaveric renal transplantation: one-year follow-up of a multicentre trial. Lancet 1983; 2: 986-989

2. Noordzij TC, Leunissen KML, van Hooff JP. Renal handling of urate and the incidence of gouty arthritis during cyclosporine and diuretic use. Transplantation 1991; 52: 64-67

3. Lin HY, Rocher LL, Mc Quillan MA et al. Cyclosporineinduced hyperuricemia and gout. NEJM 1989; 321: 287-292

4. Zollner W, Grobner W, Gresser U. Purinstoffwechsel, Unkosurika, Urikostatika. Pharmakotherapie der Gicht. In: Forth W, Henschler D, Rummel W et al, eds. Allgemeine und spezielle Pharmakologie und Toxikologie. Wissenschaftsverlag, Mannheim; 1992: 495-502

5. Mertz DP. Veranderungen der Serumkonzentration von Harnsaure unter der Wirkung von Benzbromaron. MMW 1969; 9: $491-495$

6. Begemann H, Neu 1. Die Behandlung der Urikopathie mit Benzbromaron unter besonderer Berucksichtigung der Nierenınsuffizienz. Therapiewoche 1975; 25: 2184-2192

7. Versluis DJ, Wenting GJ, Jeekel $J$ et al. Cyclosporin A-related proximal tubular dysfunction: impaired handling of uric acid. Transplant Proc 1987; 19: 4029-4030

8. Tiller DJ, Hall BM, Horvarth JS et al. Gout and hyperuricaemia in patients on cyclosporin $A$ and diuretics. Lancet 1: 1985; 453

9. Cohen SL, Boner G, Rosenfeld JB et al. The mechanism of hyperuricemia in cyclopsorin-treated renal transplant recipients. Transplant Proc 1987; 19: 1829-1830

10. Noordzij TC, Leunissen KML, van Hooff JP. letter. NEJM 1990; 322: 335

11. Chapman JR, Harding NGL, Griffiths D. Reversibility of cyclosporin nephrotoxicity after three months' treatment. Lancet 1 : $1985 ; 128-129$

12. Kothe E, Battner C, Quellhorst E et al. Behandlung der 
Hyperurikămie bei Niereninsuffizienz mit Benzbromaron. Therapiewoche 1973; 23: 2927-2933

13. Charbonnet $F$, Rossier J. La benzbromarone dans le traitement de l'hyperurioémie. Schweiz Rundsch Med Prax 1973; 44: 1337-1344

14. Flury W, Ruch HR, Montandon A. Zur Behandlung der Hyperurikamie nach Nierentransplantation. Schweiz Med Wochenschr 1977; 107: 1339-1341

15. Garryfallos A, Maoula I, Tsapas G. Evaluation of the renal mechanism for urate homeostasis in uremic patients by probenecid and pyrazinamide test. Nephron 1987; 46: 273-280
16. Steele TH, Rieselbach RE. The contribution of residual nephrons within the chronically diseased kidney to urate homeostasis in man. Am J Med 1967; 43: 876-886

17. Fox IH, Sinclair DS. The pharmacology of the hypouricemic effect of benzbromarone. Adv Exp Med Biol 1977; 76B: 328-333

18. Sorensen SB. Extrarenal disposal of uric acid. In: Kelley WN, Weiner IM, eds. Uric Acid. Springer Verlag, Berlin; 1978: 325-336

19. Vaziri ND, Freel RW, Hatch M. Enhanced enteric excretion of urate in chronic renal failure in rats. JASN; 1992; 3: 753 (Abstract)

Received for publication 15.3 .93

Accepted in revised form 14.9 .93 